\title{
Advances in Intraluminal Exfoliative Cytology of Gastric Cancer: Oncologic Implication of the Sixth Metastatic Route (Metastasis VI)
}

\author{
EDOARDO VIRGILIO ${ }^{1}$, ENRICO GIARNIERI ${ }^{2}$, MONICA MONTAGNINI ${ }^{2}$, \\ SANDRA VILLANI ${ }^{2}$, MARIA ROSARIA GIOVAGNOLI ${ }^{2}$, PAOLO MERCANTINI ${ }^{1}$, \\ GENOVEFFA BALDUCCI ${ }^{1}$ and MARCO CAVALLINI ${ }^{1}$
}

${ }^{1}$ Department of Medical and Surgical Sciences and Translational Medicine, Faculty of Medicine and Psychology, Sapienza University, St. Andrea Hospital, Rome, Italy;

${ }^{2}$ Department of Clinical and Molecular Medicine, Faculty of Medicine and Psychology, Sapienza University, St. Andrea Hospital, Rome, Italy

\begin{abstract}
Historically, analysis of intragastric exfoliative cytology (IEC) of gastric cancer (GC) was used with a diagnostic intent only. With the successful advent of endoscopic biopsy, the rate of detection of GC has improved worldwide and, as a consequence, IEC has been progressively abandoned. Today, however, there is a renewed interest in this field of research, as witnessed by several pertinent publications. As discussed in this review, in fact, currently the importance of analyzing IEC in patients with early and advanced GC seems to reside in its clinicopathological and prognostic significance. In fact, compared to non-sloughing tumors, GC exhibiting intragastric exfoliation was recently associated with an aggressive tumor phenotype (characterized by deeper infiltration of the gastric wall, lymph nodal or distant metastases, angiolymphatic and perineural invasion) and poorer prognosis. Adoption of IEC examination in routine practice might help identify patients at higher risk of developing local recurrence and peritoneal metastasis from early and advanced GC, optimizing their treatment and improving quality of life and life expectancy.
\end{abstract}

Correspondence to: Professor Edoardo Virgilio, Medical and Surgical Sciences and Translational Medicine, Faculty of Medicine and Psychology, Sapienza University, St. Andrea Hospital, via di Grottarossa 1035-39, 00189, Rome, Italy. Tel: +39 0633775693, Fax: +39 0633775322, e-mail: aresedo1992@yahoo.it, edoardo. virgilio@uniroma1.it

Key Words: Gastric cancer, gastric cytology, gastric lavage, GL, intragastric exfoliation, Metastasis VI, peritoneal seeding, ESD, review.
The study of intragastric exfoliative cytology (IEC) of gastric carcinoma (GC) started in 1882 when Rosenbach reported for the first time the presence of tumor cells in the gastric lavage of individuals affected with this type of malignancy (1). Coinciding with the worldwide success and spread of Papanicolaou staining, the heyday of IEC was from the 1940s to the 1960s; since the 1970s, succumbing to the more accurate results in diagnosis provided by the combination of endoscopy with biopsy, it was progressively abandoned $(2,3)$. Over recent years, however, a renewed interest in IEC has been generated. In 2013, in fact, Xie and colleagues found isolated cancer cells infiltrating the mesogastrium of resected GC specimens; such a finding in the mesogastrium led the authors to identify a metastatic pathway different from the four traditional routes (direct invasion, hematogenous spread, lymphatic dissemination, trancoelomic seeding) and to call it Metastasis $\mathrm{V}(4,5)$. Concomitantly, our and other study groups have decided to focus on and persist in IEC for GC: for the first time in history, however, what was investigated was not the diagnostic role of IEC but other unreported aspects, such as its clinicopathological, prognostic and predictive significance (5$8)$, as well as prophylactic or therapeutic potential $(9,10)$. Compared with its non-exfoliative counterpart, in fact, GC exhibiting intraluminal seeding has been associated with traditional aggressive features of malignancy (depth of gastric wall invasion, lymph nodaI and distant metastasis, lymphovascular and perineural emboli) and poorer prognosis (shorter survival and time to tumor progression) (11-12). Of interest, such results have been confirmed so far for early (13) and advanced (3) GC tumors, as well as GC submitted to neoadjuvant therapy (14). For such oncologicaI discoveries and implications, IEC of GC was recently identified as the sixth 
Table I. Main clinicopathological findings of literature dealing with intragastric exfoliative cytology of gastric cancer (GC).

\begin{tabular}{|c|c|c|c|c|c|c|c|c|}
\hline \multirow[b]{2}{*}{ Ref. } & \multirow[b]{2}{*}{ Study type } & \multirow[b]{2}{*}{$\mathrm{GC}, \mathrm{n}$} & \multirow[b]{2}{*}{$\mathrm{GC}$} & \multicolumn{2}{|c|}{ GL1 } & \multirow[b]{2}{*}{ Gastric status } & \multirow[b]{2}{*}{ GL method } & \multirow[b]{2}{*}{ GL volume; solution } \\
\hline & & & & Early GC & Advanced GC & & & \\
\hline 3,13 & $\mathrm{P}$ & 96 & $48 \%$ & $31 \%$ & $51 \%$ & In vivo & Blind & 1 1; Saline \\
\hline 5 & $\mathrm{P}$ & 38 & $34 \%$ & $14 \%$ & $42 \%$ & In/ex vivo & Blind & $200 \mathrm{ml}$; Saline \\
\hline 9 & $\mathrm{P}$ & 89 & $58 \%$ & $58 \%$ & $70 \%$ & In vivo & FGS & $250 \mathrm{ml} ; \mathrm{RL} / \mathrm{DW}$ \\
\hline 12 & $\mathrm{P}$ & 142 & $23 \%$ & $10 \%$ & $35 \%$ & In vivo & Blind & $50 \mathrm{ml}$; Saline \\
\hline 19 & $\mathrm{P}$ & 48 & $27 \%$ & $27 \%$ & No case & Ex vivo & No GL & No GL \\
\hline
\end{tabular}

DW: Distilled water; FGS: fibergastrosope; GL: gastric lavage; GL1: gastric lavage positive for cancer cells; P: prospective; Ref.: reference; RL: Ringer's lactate.

metastatic route attained by GC (Metastasis VI) (15). This review presents a discussion on some of the aforementioned original topics surrounding GC EIC.

\section{Literature on Collection Techniques in IEC}

There are two main ways of collecting gastric contents: The blind and the endoscopic (or direct-vision) washing method $(16,17)$. For the former, numerous variants have been described concerning both the type (normal saline; Ringer's lactate; acetate buffer, with or without mucolytic agents such as $\alpha$-chymotrypsin) and quantity (from a few milliliters to 1 liter) of solution to flush $(3,16,17)$. The direct-vision technique requires the use of fibergastroscope, thereby resulting in a more time-consuming and expensive procedure (3).

\section{Literature on Analysis Techniques of IEC}

The blind method permits only intragastric free-floating cancer cells to be retrieved, hence, the subsequent cytopathological analysis is called luminal fluid cytology (also known as washing, liquid, liquid-based or lavage cytology) $(3,16,17)$. On the other hand, fibergastroscopy allows not only the simple technique of gastric lavage, but also mechanical abrasion of the gastric walls: this is the case of brushing (or brush) cytology (17). More recently, a further examination called stamp or imprint cytology has been developed for preoperative biopsy or surgical specimens $(18,19)$.

\section{Literature on IEC in Patients with GC}

As demonstrated by previous studies, cancer cells do indeed exist in the gastric juice of patients affected with GC (including those with early GC) $(9,11,15,19)$. There are two possible ways for GC cells to be exfoliated intraluminally: one spontaneous, and one iatrogenic (after direct or indirect contact by gastroscopic biopsy, surgical manipulation or other maneuvers) $(5,19)$. For the former, the rate of unforced intragastric exfoliation of GC varies through the literature, ranging from $23.2 \%$ to $58 \%(3,5,9,12,19)$. For the latter, intraoperative acts or complications occurring during surgery of non-serosal GCs can spill the gastric contents (including the cancer cells exfoliated into it) into the peritoneal cavity, thereby recreating the same conditions when faced with serosal cancer: peritoneal seeding and the development of peritoneal metastasis (PM) $(12,20)$. The oncological significance of this possible post-surgery complication is very serious when related to the current dimension of the problem: as of 2019, in fact, half of all patients with GC who undergo radical gastrectomy die as result of PM $(11,12)$. In addition to duodenogastric reflux and other mechanisms, moreover, IEC may be responsible for some gastric stump cancers (including anastomotic site and remnant stomach) $(12,21)$. The main characteristics of the studies dealing with GC IEC are listed in Table I.

\section{Literature on IEC of Early GC Developing Metastasis After Treatment}

Early GC treated with surgery or minimally invasive techniques is associated with the development of three types of metastatic or secondary deposit: PM, port-site metastasis and metachronous gastric stump cancer. PM is a possible accident in early GC during its natural history course, as well as in the post-treatment follow-up $(5,12)$. Differently from advanced GC, however, early GC shows minimal infiltration of the gastric wall and no cancer cells floating in peritoneal cavity: hence, the four traditional metastatic routes cannot explain the development of PM in such an initial phase of disease and other pathways (such as Metastasis V and VI) might be involved $(4-6,13,15,20)$. In this regard, IEC (Metastasis VI) of early GC has been confirmed by several works $(13,19)$ (Table I) and its seeding through gastric wall perforation to the peritoneal cavity, as occurs accidentally or intentionally during endoscopic submucosal dissection or laparoscopic endoscopic cooperative surgery respectively, assessed as the main cause of early GC-related PM (22-25). As of 2019, M has been recorded in four patients with early GC who experienced gastric wall perforation during endoscopic submucosal dissection; three of them later died (22-24) (Table II). IEC of early GC can be also associated with the development of port-site metastasis after 
Virgilio et al: Endoluminal Cytology of Gastric Cancer (Review)

Table II. Literature data of patients with early gastric cancer $(G C)$ developing metastasis potentially related to intraluminal exfoliation cytology.

\begin{tabular}{cccccccc}
\hline Ref. & $\begin{array}{c}\text { Early GC, } \\
\mathrm{n}\end{array}$ & $\begin{array}{c}\text { T1a/T1b, } \\
\mathrm{n}\end{array}$ & N-Stage & Treatment & $\begin{array}{c}\text { Treatment } \\
\text { complication }\end{array}$ & $\begin{array}{c}\text { Treatment complication } \\
\text { correction }\end{array}$ & $\begin{array}{c}\text { Related metastasis } \\
\text { type }\end{array}$ \\
\hline 3,13 & 2 & $1 / 1$ & N0/N1 & $\begin{array}{c}\text { NAT + TG } \\
\text { DG + AT }\end{array}$ & None & None & AR and PMPM \\
and KT & GWP & ES & R and PM \\
22 & 1 & $0 / 1$ & N0 & ESD & GW & ES/G & PM and LM \\
23 & 2 & $1 / 1$ & N0/N0 & ESD & GWP + peritonitis & GWP & ES (P) 1$)$ \\
24 & 1 & $0 / 1$ & N0 & ESD & GWP & Endoclip + G & PS and PM \\
26 & 1 & $1 / 0$ & N0 & LADG & None & None & PS \\
27 & 1 & $0 / 1$ & N0 & NAT+LADG & None & None and PM \\
\hline
\end{tabular}

AR: Anastomotic recurrence; AT: adjuvant treatment; DG: distal gastrectomy; ES: emergency surgery; ESD: endoscopic submucosal dissection; G: gastrectomy; GWP: gastric wall perforation; KT: Krukenberg tumor; LADG: laparoscopy-assisted distal gastrectomy; LM: liver metastasis; N.A. not assessed; N0/N1: without/with lymph node metastasis; NAT: neoadjuvant treatment; PM: peritoneal metastasis; PS (PO/Cy1): peritoneal seeding (without macroscopic PM but with positive peritoneal wash cytology); R: recurrence; T1a: mucosal GC; T1b: submucosal GC; TG: total gastrectomy.

laparoscopic gastrectomy: to date, only two cases have been reported and both of them later died of $\operatorname{PM}(26,27)$ (Table II). After bleeding and gastric wall perforation (with peritoneal seeding), gastric stump cancer represents the third potential complication of endoscopic submucosal dissection. To date, although no work has considered Metastasis VI among the risk factors of this type of secondary GC $(28,29)$, we strongly suggest it should be kept in mind and such a topic be further explored in future research. More recently, in fact, some studies have demonstrated a reduction in GC IEC performing gastric lavage with distilled water. In the future, especially in the case of GWP occurring during endoscopic submucosal dissection or laparoscopic endoscopic cooperative surgery for early GC, the intraoperative use of gastric lavage with distilled water, reducing IEC and minimizing the associated risk of intraperitoneal spillage of intragastric malignant cells, could become a cogent antitumor procedure (9).

\section{Conclusion}

In the light of the results coming from our and other study groups, IEC of GC, better known as the sixth metastatic route attained by GC (Metastasis VI), is shedding renewed light on the branch of gastrointestinal cytopathology and attracting the attention of those interested and motivated in this research area.

\section{Conflicts of Interest}

The Authors declare no conflicts of interest.

\section{Authors' Contributions}

All the Authors agreed with the content of the article. Dr. Virgilio conceived the presented research. Dr. Virgilio and Dr. Mercantini performed the clinical part of the research. Dr. Giarnieri, Mrs. Montagnini, Mrs. Villani and Professor Giovagnoli performed the cytopathological analysis. Dr. Virgilio and Dr. Giarnieri contributed to the interpretation of the results. Dr. Virgilio wrote the article and performed the statistical analyses. Dr. Balducci and Dr. Cavallini helped supervise the entire project.

\section{References}

1 Rosenbach O: Über die anwesenheit von geschwulst partikeln in dem durch die magenpumpe entleerten mageninhalte bei carcinoma ventriculi. Dtsch Med Wochenschr 8: 452-454, 1882.

2 Diamantis A, Beloukas AI, Kalogeraki AM and Magiorkinis E: A brief chronicle of cytology: From Janssen to Papanicolaou and beyond. Diagn Cytopathol 41: 555-564, 2012. PMID: 22807413. DOI: $10.1002 / \mathrm{dc} .22887$

3 Virgilio E, Balducci G, Mercantini P, Giarnieri E, Giovagnoli MR, Montagnini M, Proietti A, D’Urso R and Cavallini M: Utility of nasogastric tube for medical and surgical oncology of gastric cancer: A prospective institutional study of a new and precious application of an old and economic device. Anticancer Res 38: 433-439, 218. PMID: 29277806.

4 Xie D, Osaiweran H, Liu L, Wang X, Yu C, Tong Y, Hu J and Gong J: Mesogastrium: A fifth route of metastasis in gastric cancer? Med Hypotheses 80: 490-500, 2013. PMID: 23403142. DOI: $10.1016 /$ j.mehy.2012.12.020

5 Han TS, Kong SH, Lee HJ, Ahn HS, Hur K, Yu J, Kim WH and Yang HK: Dissemination of free cancer cells from the gastric lumen and from perigastric lymphovascular pedicles during radical gastric cancer surgery. Ann Surg Oncol 18: 2818-2825, 2011. PMID: 21455599. DOI: $10.1245 / \mathrm{s} 10434-011-1620-8$

6 Virgilio E, D'Antonio C and Balducci G: Mesogastrium recurrence as expression of the fifth metastatic route of gastric cancer. Med Hypotheses 82: 403-404, 2014. PMID: 24472868. DOI: $10.1016 /$ j.mehy.2014.01.005

7 Virgilio E, Giarnieri E, Montagnini M, D’Urso R, Proietti A, Mesiti A, Giovagnoli MR, Mercantini P, Cavallini M and Balducci G: Analyzing gastric lavage of gastric cancer patients: A prospective observational study on cytopathology and determination of intragastric CEA, CA 19.9, CA 72.4, and CA 50. Acta Cytol 60: 161-166, 2016. PMID: 27096417. DOI: 10.1159/000445765

8 Virgilio E, Giarnieri E, Montagnini M, D'Urso R, Proietti A, Mesiti A, Giovagnoli MR, Mercantini P, Cavallini M and Balducci 
G: Detection of cancer cells and tumor markers in gastric lavage of patients with gastric cancer: Do these findings have a clinicopathological significant and oncological implication? Med Hypotheses 94: 1-3, 2016. PMID: 27515187. DOI: 10.1016/ j.mehy.2016.06.010

9 Ohki A, Abe N, Yoshimoto E, Hashimoto Y, Takeuchi H, Nagao G, Masaki T, Mori T, Ohkura Y and Sugiyama M: Gastric washing by distilled water can reduce free gastric cancer cells exfoliated into the stomach lumen. Gastric Cancer 21: 998-1003, 2018. PMID: 29696405. DOI: 10.1007/s10120-018-0824-z

10 Virgilio E, Balducci G, Mercantini P, Giarnieri E, Giovagnoli MR, Montagnini M, Proietti A, D’Urso R and Cavallini M: Preoperative gastric lavage in gastric cancer patients undergoing surgical endoscopic or minimally invasive treatment: An oncological measure preventing peritoneal spillage of intragastric cancer cells and development of related metastases. Med Hypotheses 114: 3034, 2018. PMID: 29602460. DOI: 10.1016/j.mehy.2018.02.023

$11 \mathrm{Yu}$ XF, Ma XQ, Hu XQ, Zhang QF and Ye ZY: Analysis of exfoliated gastric carcinoma cells attached on surgical supplies. Onco Targets Ther 7: 1869-1873, 2014. PMID: 25336978. DOI: 10.2147/OTT.S66412

12 Murata S, Yamamoto H, Yamaguchi T, Kaida S, Ishida M, Kodama H, Takebayashi K, Shimizu T, Miyake T, Tani T, Kushima R and Tani M: Viable cancer cells in the remnant stomach are a potential source of peritoneal metastasis after curative distal gastrectomy for gastric cancer. Ann Surg Oncol 23: 2920-2927, 2016. PMID: 27052647. DOI: $10.1245 / \mathrm{s} 10434-016-5219-\mathrm{y}$

13 Virgilio E, Giarnieri E, Giovagnoli MR, Montagnini M, Proietti A, D’Urso R, Mercantini P, Balducci G and Cavallini M: Early gastric cancer exfoliating into gastric lavage (GL1early GC) shows a more aggressive behavior and poorer survival compared to the non-exfoliative counterpart (GL0early GC). Anticancer Res 37: 4199-4203, 2017. PMID: 28739707.

14 Virgilio E, Giarnieri E, Giovagnoli MR, Montagnini M, Proietti A, D’Urso R, Fegiz A, Mercantini P, Balducci G and Cavallini M: Gastric lavage malignant cells (yGL) and hypohemoglobinemia (yAnemia) as new systems of tumor regression grading and prognostic prediction for gastric cancer after neoadjuvant treatment. Anticancer Res 39: 1019-1027, 2019. PMID: 30711990. DOI: 10.21873/anticanres.13208

15 Virgilio E, Giarnieri E, Giovagnoli MR, Montagnini M, Proietti A, D’Urso R, Nigri G, Mercantini P, Ramacciato G, Cavallini M and Balducci G: Presence of cancer cells in gastric lavage of gastric cancer patients as an indicator of advanced disease, predictor of tumour aggressive phenotype and independent prognostic factor for poor survivaI: The endoluminal metastatic pathway of gastric cancer and GL0/GL1 classification. Cytopathology 29: 41-48, 2018. PMID: 29063636. DOI: 10.11 11/cyt.12484

16 Schade RO: Exfoliative cytology of gastric carcinoma. Br Med J 1: 743-744, 1958. PMID: 13510786. DOI: 10.1136/bmj. 1.5073 .743

17 Ishioka K, Yamagata S, Takeda T, Ayusawa S, Naganuma E, Yamagata J, Kobiyama M, Goto M, Sato A, Umetsu Y and Toyohara T: Cytological diagnosis of early gastric cancer. Tohoku J Exp Med 118: 9-17, 1976. PMID: 964036.

18 Padmavathy F, Siddaraju N and Sistla SC: Distinction of intestinal and diffuse types of gastric adenocarcinoma on brush cytology. Acta Cytol 55: 187-192, 2011. PMID: 21325805. DOI: $10.1159 / 000320791$
19 Goto O, Shimoda M, Sasaki M, Kiguchi Y, Mitsunaga Y, Akimoto T, Ochiai Y, Fujimoto A, Maehata T, Nishizawa T, Takeuchi H, Kitagawa Y, Kameyama K and Yahagi N: Potential for peritoneal cancer cell seeding in endoscopic full-thickness resection for early gastric cancer. Gastrointest Endosc 87: 450456, 2018. PMID: 28890117. DOI: 10.1016/j.gie.2017.08.036

20 Takebayashi K, Murata S, Yamamoto H, Ishida M, Yamaguchi T, Kojima M, Shimizu T, Shiomi H, Sonoda H, Naka S, Mekata E, Okabe H and Tani T: Surgery-induced peritoneal cancer cells in patients who have undergone curative gastrectomy for gastric cancer. Ann Surg Oncol 21: 1991-1997, 2014. PMID: 24499832. DOI: $10.1245 / \mathrm{s} 10434-014-3525-9$

21 Chowdappa R, Tiwari AR, Ranganath N and Kumar RV: Is there difference between anastomotic site and remnant stump carcinoma in gastric stump cancer? A single institute analysis of 90 patients. J Gastrointest Oncol 10: 307-313, 2019. PMID: 31032099. DOI: 10.21037 /jgo.2018.12.03

22 Huh CW, Kim GJ, Kim BW, Seo M and Kim JS: Long-term clinical outcomes and risk of peritoneal seeding after endoscopic submucosal dissection for early gastric cancer: A focus on perforation during the procedure. Gut Liver, 2019. PMID: 30970443. DOI: $10.5009 /$ gnl18350

23 Hirao M, Yamada T, Michida T, Nishikawa K, Hamakawa T, Mita E, Mano M and Sekimoto M: Peritoneal seeding after gastric perforation during endoscopic submucosal dissection for gastric cancer. Dig Surg 35: 457-460, 2018. PMID: 29130978. DOI: $10.1159 / 000481715$

24 Morita A, Yabushita K, Kimura J, Oyama K, Terada I, Yamamoto S, Kaji M, Maeda K and Konishi K: A case of stage IB gastric cancer caused peritoneal dissemination in 1 year after perforation during endoscopic submucosal dissection. Jpn J Gastroenterol Surg 40: 399-404, 2007. DOI: 10.5833/jjgs.40.399

25 Hiki $\mathrm{N}$ and Nunobe S: Laparoscopic endoscopic cooperative surgery (LECS) for the gastrointestinal tract: Updated indications. Ann Gastroenterol Surg 3: 239-246, 2019. PMID: 31131352. DOI: 10.1002 /ags3.12238

26 Jang YH, Lim DH, Kim YH, Suh WY, Park KW, Song IH and Lee SI: Early gastric cancer with cellulitis-like skin metastasis. Korean J Gastroenterol 63: 39-41, 2014. PMID: 24463287. DOI: 10.4166/kjg.2014.63.1.39

27 Sakurai K, Tanaka H, Lee T, Muguruma K, Kubo N, Yashiro M, Ohira $\mathrm{M}$ and Hirakawa K: Port-site metastasis after laparoscopicassisted distal gastrectomy (LADG). Int Surg 98: 363-366, 2013. PMID: 24229024. DOI: 10.9738/INTSURG-D-13-00049.1

28 Ishida R, Kanaji S, Maehara R, Hasegawa H, Yamamoto M, Matsuda Y, Yamashita K, Matsuda T, Oshikiri T, Sumi Y, Nakamura T, Suzuki S and Kakeji Y: Significance of additional gastrectomy including endoscopic submucosal dissection scar for gastric cancer. Anticancer Res 38: 5289-5294, 2018. PMID: 30194180. DOI: 10.21873 /anticanres.12855

29 Park JY, Kim SG, Kim J, Han SJ, Oh S, Choi JM, Lim JH, Chung $\mathrm{H}$ and Jung HC: Risk factors for early metachronous tumor development after endoscopic resection for early gastric cancer. PLoS ONE 12: e0185501, 2017. PMID: 28950014. DOI: 10.1371/journal.pone.0185501 